Room, R. (2011) Drinking and intoxication when the children are around: conflicting norms and their resolutions. Addiction Research and Theory 19(5):402403.

\title{
Drinking and intoxication when the children are around: conflicting norms and their resolutions
}

For most of us in modern societies, drinking at all, and particularly drinking to intoxication, is highly structured by time and occasion. The most enduring legacy of the temperance movement, where it was strong, was to remove drinking from the workplace. Increasingly, drinking on the street is banned, and drunkenness on the street or in public is widely forbidden or criminalised. Driving a car after drinking more than a small amount is almost universally criminalised. In formal terms, then, drinking is normatively confined to "time off" from work, and mostly either to places defined in part as semi-public places for drinking bars, clubs, restaurants - or to the private space of homes, whether one's own or someone else's. In a culture like Finland, less than one-quarter of drinking is in bars and restaurants, and much of it is in someone's home; in a survey in 2000, $44 \%$ of Finns' drinking occasions in the previous week were "at home but not in connection with a meal" (Leifman, 2002).

Times and places for drinking thus overlap to a considerable extent with the times and places for childraising and family life. Both sets of activities are fitted into the hours between work and sleep. Much of the socializing and recreation of parents with young children is perforce carried on with the children around, and with parents responsible for their care and safety.

Yet it seems that social norms concerning parenting are generally disapproving of drinking at all around small children, and particularly disapproving of drunkenness in that situation. A national survey in the U.S. in 1979 found that only $28 \%$ felt that "a person should feel free to drink one or two drinks" when they were "a parent spending time with small children"; approval for this had fallen to $18 \%$ by 1990 . Only $1 \%$ in either year felt "a person should feel free to

drink enough to feel the effects" in the same situation (Greenfield \& Room, 1997).

Raitasalo and colleagues (2011) find that Finns are almost as commonly normatively opposed as Americans to drinking in the presence of small children, and like Americans are almost unanimous that one should not get drunk in their presence. Their data also allows them to look beyond the norms to examine the 
actual practices. Children under 15 years of age were present in $12 \%$ of all their parents' drinking occasions, and on one-quarter of these occasions the parent had drunk enough to feel the effects. There was thus a considerable discrepancy between expressed norms and actual practice at the population level, and not much relation between the two at the level of the individual respondent.

How do Finnish parents negotiate the conflict between norms of sociability, which often carry an expectation of drinking, and norms opposing drinking around small children? Responses to another item analysed by Raitasalo et al. suggest that for many Finns (38\%), drinking and indeed drunkenness in the presence of small children is OK so long as someone stays sober and takes care of the children. The conflict in cultural norms is in principle solved by naming one of the adults present as the designated sober child-minder.

As Raitasalo et al. point out, while such an arrangement may pay deference to an overriding norm that the children's safety has to be guaranteed, it does not deal with an issue raised by the substantial literature on parents serving as rolemodels for their children's future drinking behaviour. To this may be added a couple of other worries. How explicit is the prior designation of who will remain sober, and does the person designated in fact always stay sober? And is a sober child-minder always able to protect the children from intoxicated actions? Data from a recent Australian adult population survey suggest that children are quite commonly adversely affected by adults' drinking. Eight percent of those responding to this survey reported that one or more children they were responsible for were yelled at, criticized or verbally abused because of some adult's drinking in the last 12 months. Three percent reported that the children had witnessed serious violence in the home, and 3\% that children were left in an unsupervised or unsafe situation because of someone else's drinking (Laslett et al., 2010, p. 108).

In high-income Western societies, social trends have brought the rules of conduct for parents of young children into increasing conflict. Women are more likely to drink and to get intoxicated than in the past, and the companionate relationship ideal means that couples will often be drinking together - including at home, with the children present. Yet the general social norms against drinking and particularly against intoxication around children seem to remain strong. As Raitasalo and her colleagues show, compromises are clearly made in a situation of conflicting norms. But we still do not know much about the details of these compromises, and how they play out in reality. Their paper opens up a substantial agenda for further research: how are parenting roles defined and 
managed, and how do they interplay with the drinking expected in adult socializing at home, in societies where drinking enough to feel the effects is a part of the routine of many people's lives?

-- Robin Room

AER Centre for Alcohol Policy Research, Turning Point Alcohol \& Drug Centre;

School of Population Health, University of Melbourne;

Centre for Social Research on Alcohol \& Drugs, Stockholm University

\section{REFERENCES}

Greenfield, T. \& Room, R. Situational norms for drinking and drunkenness: trends in the U.S. adult population, 1979-1990. Addiction 92(1):33-47.

Laslett, A.-M., Catalano, P., Chikritzhs, T., Dale, C., Doran, C., Ferris, J., Jainullabudeen, T., Livingston, M., Matthews, D., Mugavin, J., Room, R., Schlotterlein, M. \& Wilkinson, C. (2010) The Range and Magnitude of Alcohol's Harm to Others. Canberra: Alcohol Education and Rehabilitation Foundation. http://www.aerf.com.au/Harm_to_Others_Full_Report_with-errata.pdf

Leifman, H. (2002) A comparative analysis of drinking patterns in six EU countries in the year 2000, Contemporary Drug Problems 29:501-548.

Raitasalo, K., Holmila, M. \& Mäkelä, P. (2011) Drinking in the presence of underage children: attitudes and behavior. Addiction Research and Theory 00:000-000. 